\title{
Ações para Incentivar Meninas do Ensino Médio a Cursar Carreiras Tecnológicas da Universidade Federal do Rio Grande do Norte
}

\author{
Idalmis Milián Sardiña ${ }^{1}$, Cristiano Maciel $^{2}$ \\ ${ }^{1}$ Escola de Ciências e Tecnologia - Universidade Federal de Rio Grande do Norte \\ (UFRN) - Campus Universitário Lagoa Nova - Natal - RN - 59078-970 - Brasil \\ ${ }^{2}$ Instituto de Computação - Universidade Federal de Mato Grosso (UFMT) Av. \\ Fernando Corrêa da Costa, 2367, Boa Esperança - Cuiabá - MT - 78060-900 - Brasil. \\ idalmismiliandect.ufrn.br, cmaciel@ufmt.br
}

\begin{abstract}
Studies show that there is a deficit in women IT courses, constituting the female least $30 \%$ of the total volume of students. On the other hand, research shows that women trained in these areas currently represent a relevant and successful percentage of the population, resulting in excellent professionals. This research continues a previous initiative to integrate the Federal University of Rio Grande do Norte (UFRN) to public high schools, promoting different articulations. Currently UFRN already performs concrete integrated activities with the State School President Roosevelt and exchange with the Havana-Cuba, for the exchange of cultural models and teaching, as well as acquisition of new experiences. This particular proposal, suggests a new action to this project, where the high school public school students know technological careers University, promoting associated activities.
\end{abstract}

Resumo. Estudos realizados apontam que existe um déficit de mulheres em cursos TI, constituindo o sexo feminino menos de 30\% do volume total de alunos. Por outro lado, as pesquisas mostram que mulheres formadas nestas áreas, atualmente, representam um percentual relevante e bem sucedido da população brasileira, resultando em excelentes profissionais. Assim, esta pesquisa dá continuidade a uma iniciativa de integrar a Universidade Federal do Rio Grande do Norte (UFRN) às escolas públicas de ensino médio, promovendo diferentes articulações. Neste momento a UFRN já executa atividades integradas concretas com a Escola Estadual Presidente Roosevelt (EEPR) de Parnamirim e um intercâmbio com a Havana-Cuba, na troca de modelos culturais e de ensino, assim como na aquisição de novas experiências. Na proposta em tela sugere-se uma nova ação a este projeto, na qual as alunas de escolas da rede pública de ensino médio possam conhecer as carreiras tecnológicas da Universidade, por meio de atividades associadas.

\section{Introdução}

Para muitos estudantes brasileiros, abrir o espaço da universidade significa também abrir as portas para um mundo distante, quase inacessível. Uma iniciativa de articulação entre a educação básica e superior foi proposta em Milián et al. (2012), de forma a aproximar os estudantes da escola pública com a universidade. Tal iniciativa buscou aumentar a integração entre os estudantes em processo de escolarização e os que 
chegaram a universidade; socializar informações sobre o universo universitário e profissional; apresentar o espaço físico da universidade; e despertar o interesse dos estudantes para com o papel social da universidade. E, desta forma, ampliar seus horizontes quanto a possibilidades de ingressar nas carreiras.

O processo de inclusão na educação se amplia e se efetiva na medida em que há oportunidade de acesso e permanência de jovens na escola. A ampliação de vagas na escola e a implementação de políticas públicas, já é uma realidade no Brasil e têm de certa forma, garantido maior inserção. Porém, o grande desafio é fazer com que estes jovens não só entrem, mas que permaneçam na escola com possibilidade de inserção no ensino superior. Nesta perspectiva, algumas estratégias organizadas coletivamente pelos grupos de profissionais que atuam nas escolas, podem ser o caminho possível para fomentar, nos adolescentes, o desejo de permanência na escola e o alcance posterior de seus objetivos pessoais. Esta premissa deve promover a construção do Projeto Político Pedagógico escolar em busca do cumprimento de sua função social possibilitar o acesso ao conhecimento socialmente construído. Paralelamente a este objetivo pedagógico, há a necessidade de alimentar "projetos de vida" coletivos e individuais, capazes de impulsionar o sujeito em busca de seus ideais e necessidades. Este é um objetivo transdisciplinar da escola, ou seja, ser capaz de levar o indivíduo a resignificar sua própria vida, redimensionando-a. Inclui-se aí, a necessidade de pensar em criar e planejar situações de articulação e vínculo com este objetivo.

Para corrigir as distorções e os altos índices de insucessos da Educação Básica, foram adotadas recentemente, algumas políticas públicas das quais se destacam: o Pacto Nacional pela Alfabetização na Idade Certa (PNAIC/2012) e o Pacto Nacional pelo Fortalecimento do Ensino Médio (2013). Nessa perspectiva, distintas ações propostas no projeto inicial (padrinhos das escolas, intercâmbios socioculturais com outros países e atividades extracurriculares culturais e de pesquisa), já estão sendo desenvolvidas na UFRN, como expõe Milian et al. (2015).

O presente trabalho representa a inclusão de uma nova ação no projeto, que busca criar ambientes de interlocução com jovens do sexo feminino na interface da educação formal e não formal (Trilla, 2008). O objetivo principal é identificar a vocação destas jovens em relação a áreas de Tecnologia da Informação (TI) com vistas a um possível futuro ingresso em cursos TI da UFRN, como por exemplo, nos bacharelados do Instituto Metrópole Digital e da Escola de Ciência e Tecnologia. O projeto ora proposto está em consonância com as metas do Plano Nacional da Educação (PNE), recentemente aprovada na forma de Lei (Lei no. 13.005 de 25 de Junho de 2014). Este, insere-se junto as metas 3 e 12 que tratam respectivamente da universalização do Ensino Médio e a democratização do acesso ao Ensino Superior. Acredita-se que trabalho possa contribuir no crescimento do número de mulheres interessadas nestas carreiras.

\section{Da proposta e sua origem}

Neste trabalho uma nova ação foi proposta, como parte do projeto de ensino médio iniciado anteriormente em Milián et al. (2012). A ação incluída visa o aumento da participação de mulheres estudando em cursos TI da UFRN. Neste sentido, algumas atividades estão sendo definidas e outras já estão em andamento, como por exemplo, alguns professores de cursos tecnológicos, em particular da Escola de Ciência e Tecnologia e do Instituto Metrópole Digital da UFRN, promovem palestras e atividades de extensão, que atingem especificamente grupos de alunas do segundo ano do ensino 
médio da Escola Estadual Presidente Roosevelt (EEPR). A proposta coincide e tem aderência com os objetivos do Programa Meninas Digitais da Sociedade Brasileira de Computação ${ }^{1}$, iniciado em 2011. O objetivo deste programa é divulgar a área de Computação para despertar o interesse de estudantes do ensino médio/tecnológico ou dos anos finais do ensino fundamental, para que conheçam melhor a área e, desta forma, motivá-las a seguir carreira em Computação (Maciel; Bim, 2016). As atividades deste programa são realizadas por meio de projetos realizados em diferentes instituições do Brasil e de forma diversificada: oferta de minicursos e oficinas; realização de dinâmicas; palestras com estudantes e profissionais que já atuam na área compartilhando suas experiências etc.

As primeiras instituições que já executam algumas das atividades propostas para esta ação são a UFRN e a EEPR. A UFRN, com sede na cidade do Natal, é o principal centro universitário do estado de Rio Grande do Norte e uma das dez maiores universidades federais do Brasil em número de alunos de graduação (INEP, 2015). A EEPR se destaca por iniciar no ano 2012 uma nova metodologia de ensino, o ensino médio inovador e apresenta uma equipe de professores qualificados com cursos de pósgraduação.

Com o trabalho realizado desde 2012 no projeto, um dos resultados obtidos na EEPR, foi o incremento da motivação dos estudantes a ingressar em cursos superiores. Mais de $50 \%$ dos alunos do $3^{\circ}$ ano desta escola matricularam em universidades públicas e privadas (Milián et al., 2015). Outro resultado importante foi eles conhecer o funcionamento e as possibilidades oferecidas pelas universidades federais para os estudantes, como bolsas de estudo, intercâmbios com outros países etc. Uma feira de civilizações e um intercâmbio cultural com Cuba (Milián et al., 2014), foram também ações anteriores que levaram os alunos a embarcarem em uma viagem de conhecimento sobre povos e nações, em seus aspectos geo-históricos e culturais (Sacristan, 2002).

Já a nova ação proposta neste trabalho e que começou a ser implementada recentemente pela UFRN, está direcionada a trabalhar somente com grupos de estudantes do sexo feminino de escolas de ensino médio. O objetivo principal é apresentar a estas jovens distintas áreas TI dentro da Universidade, assim como começar a criar algumas habilidades em programação e desenvolvimento de jogos. Para o próximo semestre foram planejados alguns cursos (Web, Banco de dados, HTML, Androide, Redes etc.) que serão dados na escola EEPR por professores da Escola de Ciência e Tecnologia da UFRN. Por outro lado, visitas semanais ao Instituto Metrópole Digital foram programadas e vão permitir as alunas que participam da ação, conhecer os diferentes laboratórios de informática, o Data center, ou seja, a infraestrutura de TI em geral, mostrando assim detalhes da arquitetura dos computadores, das características da rede e o funcionamento da internet.

A interdisciplinaridade, tão discutida nos meios acadêmicos, é inerente às ações de extensão. Com a introdução da ação proposta, a computação será uma nova disciplina inserida na EEPR para grupos específicos. Neste sentido, a participação dos sujeitos nos projetos desta natureza promove, não somente a interdisciplinaridade, mas também a compreensão da abrangência da educação não formal entendida como um processo sociopolítico, tecnológico, cultural e pedagógico para a formação integral da cidadania (Gohn, 2010).

\footnotetext{
${ }^{1}$ http://sbc.org.br/institucional-3/meninas-digitais
} 
Cabe salientar que um fator que distingue os estudantes das instituições particulares em relação aos das públicas é o acesso a informação; fato que é oriundo de questões referentes aos próprios recursos que a escola oferece (corpo docente, material didático, equipamentos, estrutura física da instituição) ou até mesmo das próprias condições sociais do estudante. Sendo assim, por acreditarem que existe uma considerável discrepância, qualitativa e quantitativa no conteúdo assimilado no ensino médio, grande parte desses alunos de escolas públicas sentem-se em desvantagem frente aos alunos de escolas privadas. Alguns pensam que mesmo após o ingresso na universidade será difícil acompanharem o curso, por disporem de menores recursos financeiros.

\section{Discussões}

O objetivo é ir além, avançando qualitativamente por distintos caminhos, no relacionamento entre a academia e o seu público-alvo: os estudantes de ensino médio. Todavia, na etapa atual, ações específicas com meninas do ensino médio, em especial de Escola Públicas, estão sendo planejadas, em consonância com o Programa Meninas Digitais.

Crê-se que a experiência dos projetos anteriores, de atuação junto ao Ensino Médio, é salutar para entender esse contexto e buscar alternativas viáveis para o projeto. As atividades extensionistas possibilitam criar ambientes privilegiados através da qual os estudantes de graduação, professores e pesquisadores, podem e devem se permitir, sair do seu cotidiano das ações formais de ensino aprendizagem e adentrar nas reflexões sobre uma nova cultura organizacional que exige a aprendizagem de habilidades extracurriculares.

As mudanças para uma visão mais ampliada da educação, para a inovação dos canais existentes, para o estabelecimento de alianças e utilização de recursos de forma a universalizar o acesso à educação e fomentar a equidade (Gohn, 2010), só poderão encontrar ressonâncias a partir das ações dos sujeitos despertados para tal possibilidade por meio de atividades que o ambiente de extensão possibilita (Thiollent, 1985). Neste sentido, este trabalho vislumbra a continuidade das ações propostas em Milián et al. (2015), inserindo o objetivo proposto neste trabalho.

\section{Referências}

Brasil. (2014) "Lei do Plano Nacional da Educação (PNE)". Lei no. 13005 de 25 de Junho de 2014. Presidência da República, Casa Civil.

Ministério da Educação. Manual do pacto: Pacto pela Alfabetização na Idade Certa: o Brasil do futuro com o começo que ele merece. Brasília, DF, 2012.

. Ministério da Educação. Portaria $n^{0} 1140$, de 22 de novembro de 2013. Pacto Nacional pelo Fortalecimento do Ensino Médio, Brasília, DF, 2013.

Gohn, M. G. (2010) "Educação não formal e o educador social - atuação no desenvolvimento de projetos sociais". São Paulo, Cortez, 2010.

INEP (2015) "Resumo Técnico da Educação Superior 2013”. Diretoria de Estatísticas Educacionais DEED, Instituto Nacional de Estudos e Pesquisas Educacionais Anísio Teixeira, Brasília-DF, 82 p. 
Maciel, C., Bim, S. A. (2016) "Programa Meninas Digitais - ações para divulgar a Computação para meninas do ensino médio". In: Computer on the Beach 2016, Florianópolis, SC. pp. 327-336.

Milián, I. et al. (2015) "Atividades de extensão propostas para aproximar a UFRN às escolas públicas de ensino médio". XIII Congresso Latinoamericano de Extensão Universitária de Educação Superior, Havana. Cuba

Milián, I. et al. (2014) "Ações para Aproximar a Universidade com Escolas da Rede Pública de Ensino Médio no Brasil". 9. Congresso Internacional de Educação Superior - Universidade 2014, Havana. Cuba

Milián, I. et al. (2012) "Integração dos ensinos fundamental, médio e superior no Brasil: Uma experiência da Universidade Federal de Rio Grande do Norte". $8^{\circ}$. Congresso Internacional de Educação Superior - Universidade 2012, Havana. Cuba

Sacristan, G. (2002) "Educar e Conviver na Cultura Global”. Artmed.

Thiollent, M. (1985) "Metodologia da pesquisa-ação". SP: Cortez: Autores Associados (Coleção temas básicos de pesquisa-ação).

Trilla, J. (2008). “A educação não formal". In: ARANTES, Valéria Amorin (org.). Educação formal e não-formal: pontos e contrapontos. São Paulo: Summus, p. 15-55. 